\title{
Neutronic Analysis of a Thorium-Fueled Reduced Moderation Boiling Water Reactor
}

\author{
Dayu Fajrul Falaakh, Alexander Agung ${ }^{\#}$, Andang Widi Harto \\ Department of Nuclear Engineering and Engineering Physics, Faculty of Engineering, \\ Universitas Gadjah Mada, Jalan Grafika 2, Yogyakarta, 55281, Indonesia \\ ${ }^{\#}$ E-mail: a_agung@ugm.ac.id
}

\begin{abstract}
A study about Resource Renewable Boiling Water Reactor (RBWR) core, a reduced moderation boiling water reactor that features the breeding ratio larger than 1 was conducted. This study focuses on the neutronic performances of the core and aims to investigate the core sustainability when using thorium as the main fertile fuel. A fuel-self-sustaining core with high burnup set as the design target. ${ }^{233} \mathrm{U}+\mathrm{Th}$ were used as the initial fuel, and the impact of initial fissile $\left({ }^{233} \mathrm{U}\right)$ content in the core fissile zone on the core neutronic performances was evaluated. Parameters related to the neutronic performances such as the core burnup, fissile breeding, and fissile inventory ratio (FIR) are considered in this study. From these results, it was confirmed that it is feasible to create a selfsustaining fuel cycle system using thorium fueled RBWR. However, there was a trade-off between the core burnup and fissile breeding that can be a significant challenge in the development of this system. Evaluating the other design variables may be considered to address this challenge. The further study to analyze the safety performances of the core is required to arrive at a safe and reliable reactor system.
\end{abstract}

Keywords - thorium; reduced moderation; neutronics; SERPENT.

\section{INTRODUCTION}

Nuclear power is one of the most promising answers to meet the increased expectation for electricity in the world without increasing greenhouse-effect gas emission. On the other hand, to ensure the sustainability of nuclear power, the current open fuel cycle is not sufficient. It is essential to establish a closed fuel cycle, and nuclear recycle system. The generation IV nuclear reactors are expected to play a major role in an open fuel cycle, but they have not been commercialized yet. On the other hand, Light Water Reactor (LWR) is a verified technology and has an outstanding commercial operation record. Thus, the use of LWR to establish a closed fuel cycle is preferable. To achieve a closed fuel cycle, LWR should be designed to be fuel-selfsustaining. A fuel-self-sustaining LWR design is resource Renewable Boiling Water Reactor (RBWR). RBWR features a small pitch-to-diameter ratio (P/D), hexagonal lattice, and large exit void fraction to achieve an epithermal to fast neutron energy spectrum [1, 2, 3].

Hitachi initially developed the RBWR concept was fueled with depleted uranium (DU) as the fertile fuel and transuranium elements (TRUs) that contain fissile plutonium (Puf). It was designed to create a hard spectrum BWR that features fuel sustainability by generating Puf from DU or efficient incineration of radioactive waste from the long- lived TRUs generated as byproducts of the fission of uranium fuel [2]. However, there are several concerns regarding this TRU-DU fueled RBWR, and one of them is the uncertainty of void reactivity feedback [1] which is a vital safety characteristic of light water moderated reactor.

Another option is replacing the depleted uranium with thorium as the main fertile fuel. Thorium is a promising candidate to be used as nuclear fuel. Thorium based fuel cycle has great potential in improving the sustainability of nuclear energy. Thorium based fuel cycle will indeed produce considerably less plutonium and minor actinides than conventional fuel cycle $[4,5,6]$. Thus, developing the utilization of thorium-based fuel cycle for RBWR will be promising.

${ }^{233} \mathrm{U}$ has a much flatter fuel reproduction factor with energy in comparison with ${ }^{239} \mathrm{Pu}$ [7]. The fast fission cross section of ${ }^{232} \mathrm{Th}$ has a lower value and higher threshold than that of ${ }^{238} U$ [2]. Therefore, the void reactivity of RBWR core fueled by $\mathrm{Th}^{2}{ }^{233} \mathrm{U}$ has the negative spectral component. The $\mathrm{Th}-{ }^{233} \mathrm{U}$ based fuel cycle also provides more efficient breeding in the epithermal flux spectrum than ${ }^{233} \mathrm{U}_{-}^{239} \mathrm{Pu}$ cycle.

In this study, the core of a thorium-fueled RBWR is investigated. The thermal power capacity of the core is about 1000 MW. The core features a radially homogeneous fuel composition and hexagonal assemblies in which the fuel rods were arranged in a hexagonal tight-lattice. The core 
characteristics are evaluated by burnup calculations on the core model loaded with all fresh fuel. This study focuses on the neutronic performances of the core and aims to assess the core sustainability when using thorium as the main fertile fuel. The target of a fuel-self-sustaining core design with high burnup was also made.

The impact of the fissile fuel content in the fissile zone on the core neutronic behavior is explored. The parameters related to neutronic behavior such as the core burnup and fissile breeding are considered in this study. Another significant quantity is the fissile inventory ratio (FIR). The FIR for this study is defined as the time-dependent mass of all fissile isotopes and ${ }^{233} \mathrm{~Pa}$ contained in the fuel divided by the initial mass of ${ }^{233} \mathrm{U}$ which is the only fissile isotope contained in the initial core. ${ }^{233} \mathrm{~Pa}$ has a major role in thorium-based fuel cycle as it accumulates in the fuel due to its half-life of 27 days. Thus, due to the beta decay of ${ }^{233} \mathrm{~Pa}$ into ${ }^{233} \mathrm{U}$, the amount of ${ }^{233} \mathrm{U}$ will continue to increase in the discharged fuel during the cooling period. An extended period of cooling that enables the completion of ${ }^{233} \mathrm{U}$ formation from the beta decay of ${ }^{233} \mathrm{~Pa}$ before reprocessing can take place will maximize the sustainability of thorium fuel cycle. The value of FIR represents the core sustainability, and it should be at least 1 to arrive at a fuelself-sustaining core design.

\section{MATERIAL AND METHOD}

The neutronic calculations in this study were performed using SERPENT [8,9], which is a continuous energy Monte Carlo (MC) neutron transport code developed at VTT research center in Finland. In these calculations, the nuclear data library based on the evaluated file ENDF/B-VII were used. The burnup calculation is performed on the Th fueled reduced moderation BWR core by using 3-dimensional calculation model. The major specifications of the calculation model are summarized in Table 1.

TABLE I

SPECIFICATIONS OF THE CALCULATION MODEL

\begin{tabular}{|l|c|}
\hline \multicolumn{1}{|c|}{ Specification } & Value \\
\hline Thermal power, MWth & 1000 \\
\hline Core height $\left(H_{\text {core }}\right), \mathrm{m}$ & 2.4 \\
\hline Core diameter $\left(D_{\text {core }}\right), \mathrm{m}$ & 4.15 \\
\hline Number of fuel assemblies & 282 \\
\hline Number of pins per assembly & 217 \\
\hline Fuel rod outer diameter, cm & 1.3 \\
\hline Fuel pitch-to-diameter ratio & 1.43 \\
\hline Fissile zone length, cm & 80 \\
\hline Upper blanket zone length, cm & 55 \\
\hline Lower blanket zone length, cm & 55 \\
\hline Exit void fraction, $\%$ & 43 \\
\hline
\end{tabular}

The core model consists of 282 hexagonal fuel assemblies, each of which consists of 217 fuel rods with the outer diameter of $13.0 \mathrm{~mm}$ arranged in gaps of $1.3 \mathrm{~mm}$ width and the $0.6 \mathrm{~mm}$ thick clad which is made of zircaloy. The core has $4.15 \mathrm{~m}$ diameter and $1.9 \mathrm{~m}$ total height which consists of two $0.55 \mathrm{~m}$ high axial blanket zones and an axial fissile zone with $0.8 \mathrm{~m}$ high between them. Both blanket zones are made of made of $\mathrm{ThO}_{2}$, and the fissile zone is made of a mixture of ${ }^{233} \mathrm{UO}_{2}$ and $\mathrm{ThO}_{2}$. Since a boiling water cooled reactor has a robust axial variation in the coolant density, the coolant channel of the calculation model is divided into 9 axial zones, and the axial zone-dependent coolant density is calculated based on the assumption of cosine axial power distribution [9]. The exit void fraction is 0.43 , inlet water density is approximately $0.74 \mathrm{~g} / \mathrm{cm}^{3}$, and water density at the exit is approximately $0.08 \mathrm{~g} / \mathrm{cm}^{3}$. Figure 1 shows the cross-sectional of the fuel assembly while Figure 2 shows the cross-sectional view of the core.

The burnup calculation simulates the long-term changes in the composition of nuclear fuel and other materials under irradiation as well as the resulting changes in neutronic properties of the core system [11]. In MC burnup calculation, the entire irradiation period is divided into a number of time steps, and the calculations include two distinct parts: the transport and depletion solver [12]. The transport solver calculates steady-state neutron flux and cross-sections for given material compositions by solving the neutron transport equation. The neutron fluxes and cross sections obtained from transport calculation are then used to compute the neutron-induced reaction rates. The depletion solver calculates material changes over a time-step with fixed microscopic reaction rates; this part requires solving the Bateman depletion equations. These two parts are then combined to a burnup calculation and solved in a sequential manner using so-called predictor-corrector algorithm [12, 13].

In the calculations of this study, the Bateman depletion equations were solved using the matrix exponential method based on the Chebyshev Rational Approximation Method (CRAM) $[14,15,16]$, which is used by default in SERPENT.

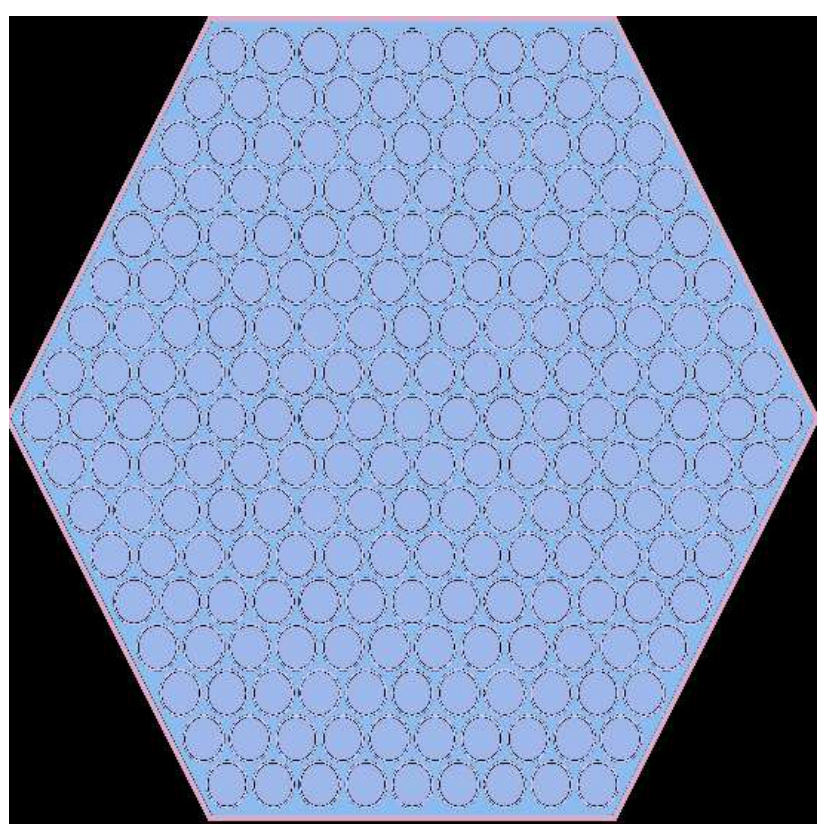

Fig 1. Horizontal cross section of RBWR fuel assembly model in SERPENT 


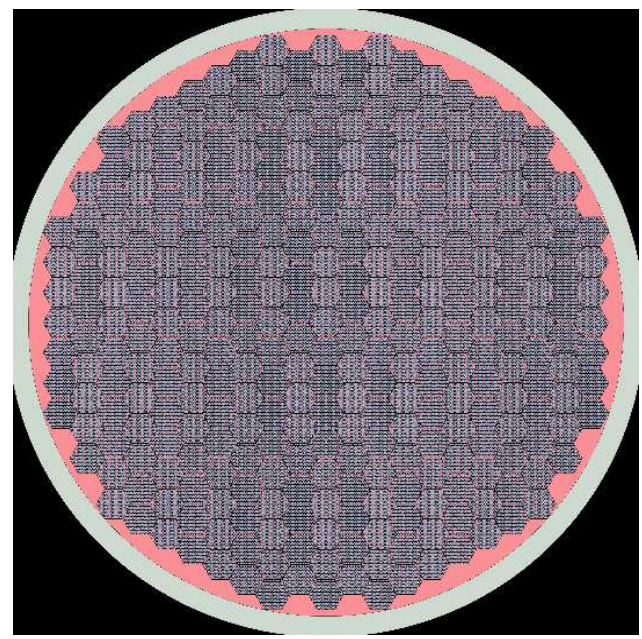

(a)

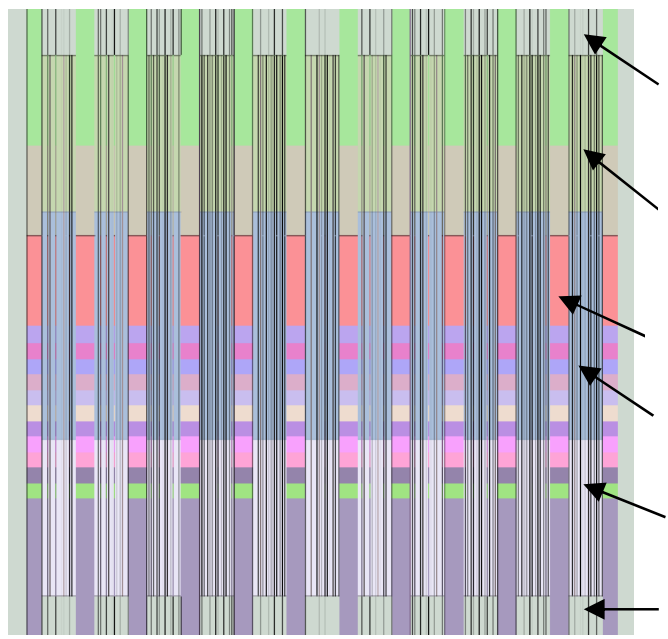

(b)

Upper reflector

Upper blanket

Coolant channel

Fissile

Lower blanket

Lower reflector

Fig 2. Horizontal (a) and vertical (b) cross section of RBWR core model in SERPENT

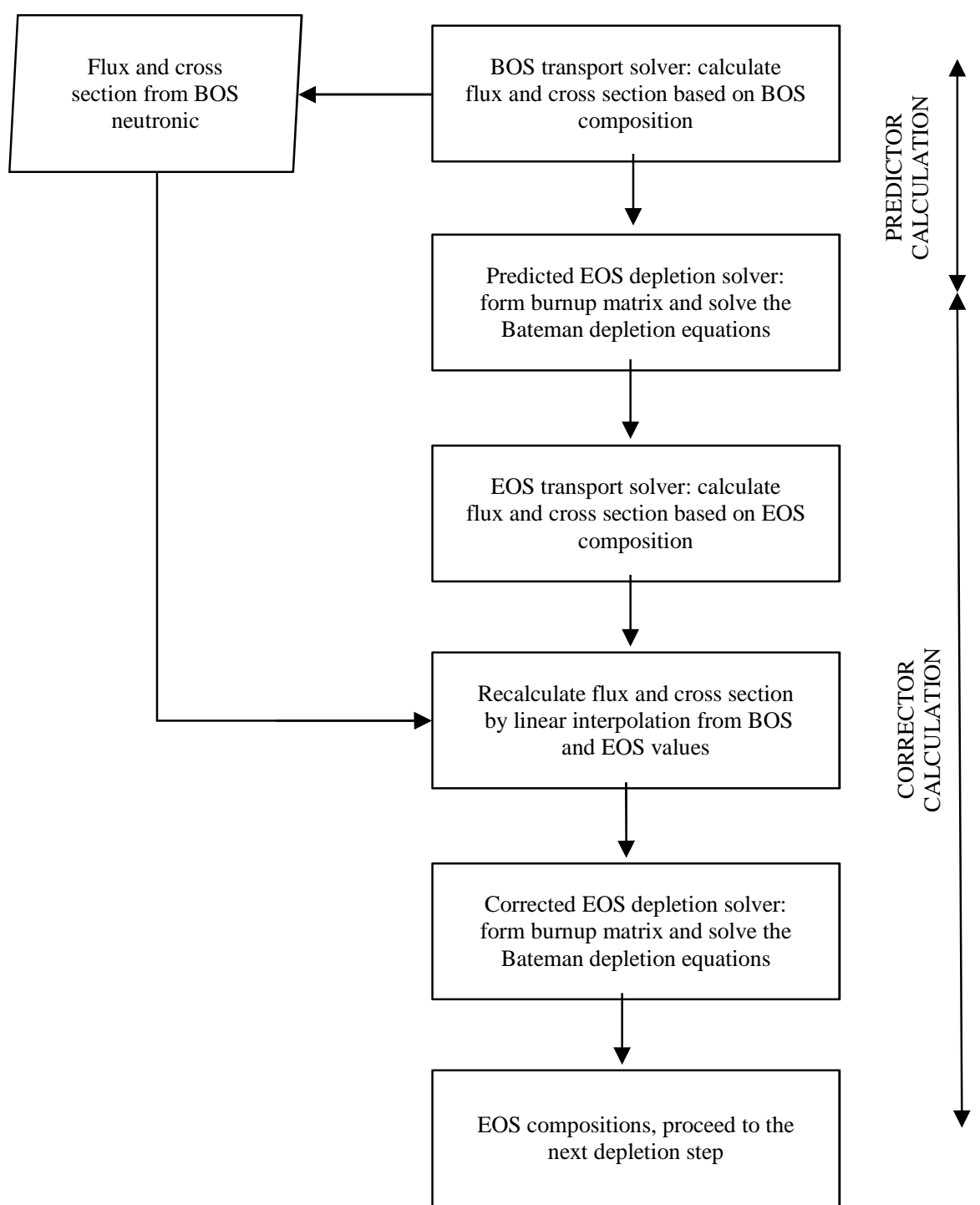

Fig 3. The flowchart of burnup calculation in this study 
In the burn-up calculation, SERPENT code uses an internal routine for solving a set of Bateman equations, which are formulated as [14]:

$$
\begin{gathered}
\frac{d N_{j}}{d t}=\sum_{i \neq j} S_{i \rightarrow J}-\lambda_{j} N_{j}-\varphi \sigma_{j} N_{j} \\
N_{j}(0)=N_{0}, \quad j=1, \ldots, n
\end{gathered}
$$

where $N_{j}$ is the atomic density of nuclide $j, S_{i \rightarrow J}$ is the production rate of nuclide $j$ in decay, transmutation and fission reactions, $\lambda_{j} N_{j}$ is the radioactive decay rate of nuclide $j$, and $\varphi \sigma_{j} N_{j}$ is the transmutation rate of nuclide $j$, including fission.

In the matrix exponential method $[14,15,16]$, the depletion problems are formulated in matrix notation as follows.

$$
n^{\prime}=A n, n(0)=n_{0},
$$

This matrix form has the matrix exponential solution:

$$
n(t)=e^{A t} n_{0}
$$

where $n \in \mathbb{R}^{n}$ is the nuclide concentration vector and $A \in \mathbb{R}^{n \times n}$ is the burnup matrix containing the generalized transmutation coefficients characterizing the total production and loss rates of the nuclides in irradiated materials. The nuclides production, as well as loss, can be caused by radioactive decay and neutron-induced reactions. The transmutation coefficients for these reactions can respectively be calculated with the following equations [13]:

$$
\begin{gathered}
\lambda_{f}=\gamma \varphi \sigma_{f} \\
\lambda_{n f}=\varphi \sigma_{n f}
\end{gathered}
$$

where $\lambda_{n f}$ and $\lambda_{f}$ are the transmutation coefficients for nonfission and fission neutron-induced reactions. The transmutation coefficients for radioactive decay $\left(\lambda_{d}\right)$ are calculated by the multiplication of the decay constant and branching ratio, which along with the fission yields $(\gamma)$ are read from ENDF format data files. The neutron flux $(\varphi)$ and cross section $(\sigma)$ are calculated by solving the neutron transport problem. The calculation methodology used in this study can be explained with the flowchart in Figure 3.

The calculations can be divided into two parts. The first part is the predictor calculation, during which the neutron transport equation for the beginning of step (BOS) material compositions is solved to calculate neutron fluxes and crosssections. These data are then combined with the radioactive decay constants, branching ratios and fission yields which are read from data libraries to calculate the transmutation coefficients that are used to form the burnup matrix. Materials are depleted over the time interval. The depletion problems are solved to obtain predicted material compositions at the end of the step (EOS). The second part is the corrector calculation, in which the EOS material compositions are corrected using the average of BOS and EOS neutron fluxes and cross sections, which corresponds to a linear interpolation between the two points.

\section{RESULTS AND DISCUSSION}

The core burnup calculations were performed to simulate the long-term neutronic behaviors of the core. The total burnup interval in the calculations is $40 \mathrm{MWd} / \mathrm{kg}$, which was divided into some steps with lengths ranged from 0.4 $\mathrm{MWd} / \mathrm{kg}$ to $2 \mathrm{MWd} / \mathrm{kg}$. The core was initially loaded with all fresh fuel which has uniform composition radially. The fissile zone composition in the initial core is varied to be $9.35 \%{ }^{233} \mathrm{U}$ and $90.65 \% \mathrm{Th}, 9.85 \%{ }^{233} \mathrm{U}$ and $90.15 \% \mathrm{Th}$ and $10.35 \%{ }^{233} \mathrm{U}$ and $89.65 \% \mathrm{Th}$, while the blankets on the top and bottom of it were only loaded with Th. The variation of fuel composition at the beginning of the cycle (BOC) used in this study is shown in Table 3.

TABLE II

SPECIFICATIONS OF THE CALCULATION MODEL

\begin{tabular}{|c|c|c|c|}
\hline \multirow{2}{*}{ No. } & \multicolumn{3}{|c|}{ Initial loading fuel composition } \\
\cline { 2 - 4 } & $\begin{array}{c}\text { Upper } \\
\text { blanket } \\
\text { zone }\end{array}$ & $\begin{array}{c}\text { Lower } \\
\text { blanket } \\
\text { zone }\end{array}$ \\
\hline 1. & $\mathrm{ThO}_{2}$ & $\begin{array}{c}90.65 \% \mathrm{ThO}_{2}+ \\
9.35 \% \mathrm{UO}_{2}\end{array}$ & $\mathrm{ThO}_{2}$ \\
\hline 2. & $\mathrm{ThO}_{2}$ & $90.15 \% \mathrm{ThO}_{2}+$ & $\mathrm{ThO}_{2}$ \\
& & $9.85 \% \mathrm{UO}_{2}$ & \\
\hline 3. & $\mathrm{ThO}_{2}$ & $\begin{array}{c}89.65 \% \mathrm{ThO}_{2}+ \\
10.35 \% \mathrm{UO}_{2}\end{array}$ & $\mathrm{ThO}_{2}$ \\
\hline
\end{tabular}

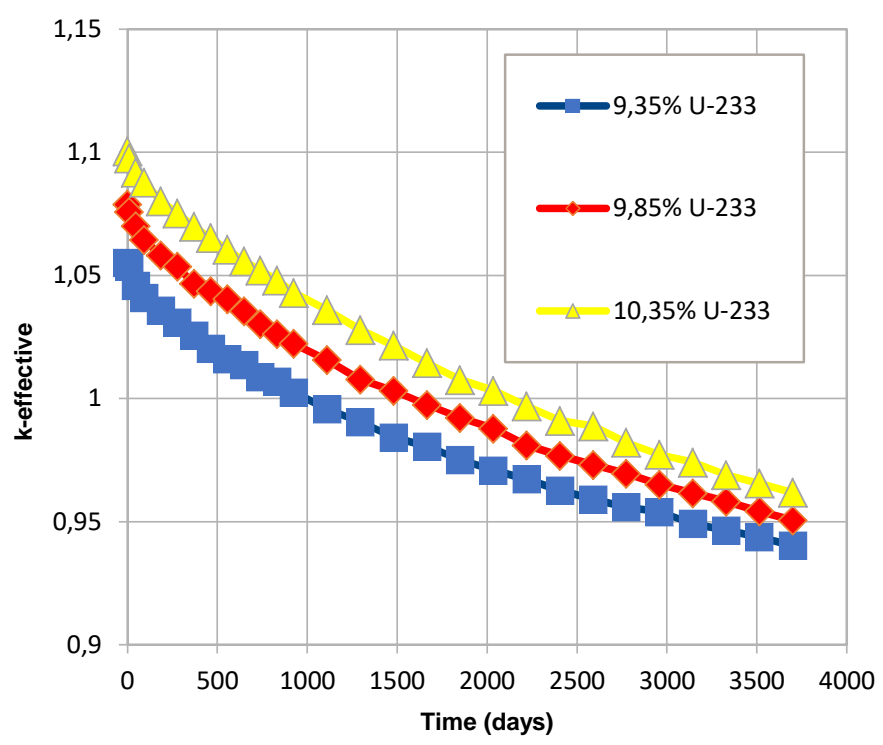

Fig 4. k-eff variation with burnup of RBWR core

Figure 4 shows the variation of effective multiplication factor $\left(\mathrm{k}_{\mathrm{eff}}\right)$ versus burnup and time for each initial fuel composition. If $\mathrm{k}_{\text {eff }}$ value is set to be 1.0 at the end of the cycle (EOC), the figure indicates that the fuel burnup and cycle duration were extended as the content of ${ }^{233} \mathrm{U}$ in fissile zone increases. The core burnup and cycle duration were respectively about $10 \mathrm{MWd} / \mathrm{kg} \mathrm{HM}$ and 925 days for ${ }^{233} \mathrm{U}$ content in fissile zone of $9.35 \%, 16 \mathrm{MWd} / \mathrm{kg} \mathrm{HM}$ and 1480 days for ${ }^{233} \mathrm{U}$ content of $9.85 \%$ in fissile zone, and 22 
$\mathrm{MWd} / \mathrm{kg} \mathrm{HM}$ and 2035 days for ${ }^{233} \mathrm{U}$ content of $10.35 \%$ in the fissile zone.

The mass variation of ${ }^{233} \mathrm{U}$ and ${ }^{232} \mathrm{Th}$ in the core as a function of time are shown in Figure 5(a) and 5(b), respectively. Figure 5(a) indicates that after decreasing initially, the inventories of ${ }^{233} \mathrm{U}$ increase when the breeding rate of ${ }^{233} \mathrm{U}$ is larger compared to its burning rate. ${ }^{232} \mathrm{Th}$ transmutation causes the ${ }^{233} \mathrm{U}$ breeding. Figure 5(b) shows the decreased ${ }^{232} \mathrm{Th}$ inventories. It also can be seen that increasing ${ }^{233} \mathrm{U}$ content in fissile zone results in the decreased burn rate of ${ }^{232} \mathrm{Th}$ that causes a reduction in the growth rate of ${ }^{233} \mathrm{U}$.

The mass variation of ${ }^{233} \mathrm{~Pa}$ and the fissile isotopes excluding ${ }^{233} \mathrm{U}$ in the core as a function of time are shown in Figure 6(a), 6(b) and 6(c). Figure 6(a) shows that the inventories of ${ }^{233} \mathrm{~Pa}$ increase rapidly with time until reach a point where the breeding rate of ${ }^{233} \mathrm{~Pa}$ equal to its loss rate. Figure 6(b) shows the breeding of ${ }^{235} \mathrm{U}$. Figure 6(c) reveals that the fissile plutonium $\left({ }^{239} \mathrm{Pu}+{ }^{241} \mathrm{Pu}\right)$ breeding rate delayed initially and dramatically increased after an extended period. It can be seen that the inventory of ${ }^{233} \mathrm{~Pa}$ is comparable to the ${ }^{235} \mathrm{U}$ inventory, and the fissile plutonium inventory is much smaller than that of ${ }^{235} \mathrm{U}$ and ${ }^{233} \mathrm{~Pa}$. These results indicate that ${ }^{233} \mathrm{~Pa}$ is an important factor in the sustainability of the thorium fuel cycle. By waiting for the entire ${ }^{233} \mathrm{~Pa}$ contained in the discharged fuel to undergo beta decay to become ${ }^{233} \mathrm{U}$ during the cooling period before the reprocessing can take place, the amount of fissile fuel in the reprocessed fuel can be maximized. Thus, ${ }^{233} \mathrm{~Pa}$ is accounted in calculating the FIR value in this study.

The variation of FIR value as a function are shown in Figure 7. The FIR value is calculated using the following equation:

$$
F I R(t)=\frac{\sum M_{F i s s i l e}(t)+M_{P a-233}(t)}{M_{U-233}(0)}
$$

where $M$ is the isotope mass and $t$ is time. It can be seen from the figure that the FIR value is-improved as the initial content of ${ }^{233} \mathrm{U}$ increases.

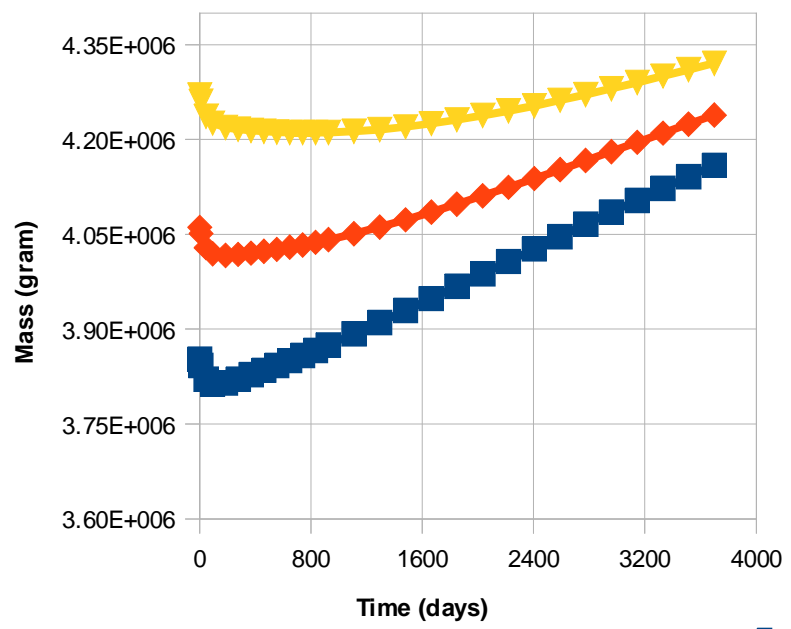

(a)
The neutronic analysis results of this study for each initial content of ${ }^{233} \mathrm{U}$ are summarized in Table 3 . As written in section 1 that the FIR value is required to be at least 1 to achieve a fuel-self-sustaining core design. The FIR value at the EOC for each initial content of ${ }^{233} \mathrm{U}$ is more than 1 which means a fuel-self-sustaining core design is achieved in this study.

TABLE III

SUMMARY OF ANALYSIS RESULTS

\begin{tabular}{|c|c|}
\hline \multicolumn{2}{|c|}{$9.35 \% 233 \mathrm{U}$ case } \\
\hline Core burnup (MWd/kg) & 10 \\
\hline Cycle length (days) & 925 \\
\hline BOC fissile inventory (tonne) & 3852300.000 \\
\hline EOC fissile Inventory (tonne) & 3931510.394 \\
\hline EOC FIR & 1.021 \\
\hline \multicolumn{2}{|c|}{$9.85 \%{ }^{233} \mathrm{U}$ case } \\
\hline Core burnup (MWd/kg) & 16 \\
\hline Cycle length (days) & 1480 \\
\hline BOC fissile inventory (tonne) & 4061100.000 \\
\hline EOC fissile Inventory (tonne) & 4135380.031 \\
\hline EOC FIR & 1.018 \\
\hline \multicolumn{2}{|c|}{$10.35 \%{ }^{233} \mathrm{U}$ case } \\
\hline Core burnup (MWd/kg) & 22 \\
\hline Cycle length (days) & 2040 \\
\hline BOC fissile inventory (tonne) & 4270100 \\
\hline EOC fissile Inventory (tonne) & 4307583.07 \\
\hline EOC FIR & 1.008 \\
\hline
\end{tabular}

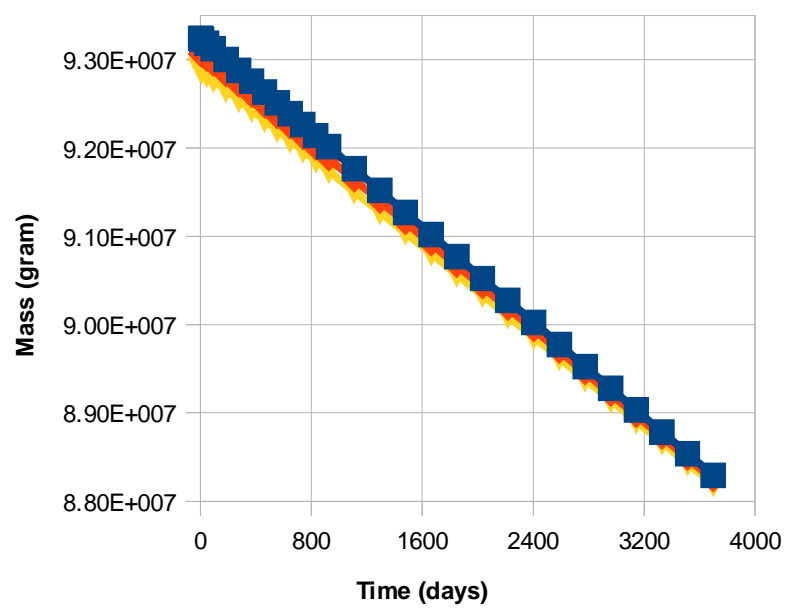

(b)

Fig 5. (a) Mass variatio6 $6 \mathbb{f}^{233} \mathrm{U}$. (b) Mass variation of ${ }^{232} \mathrm{Th}$ 


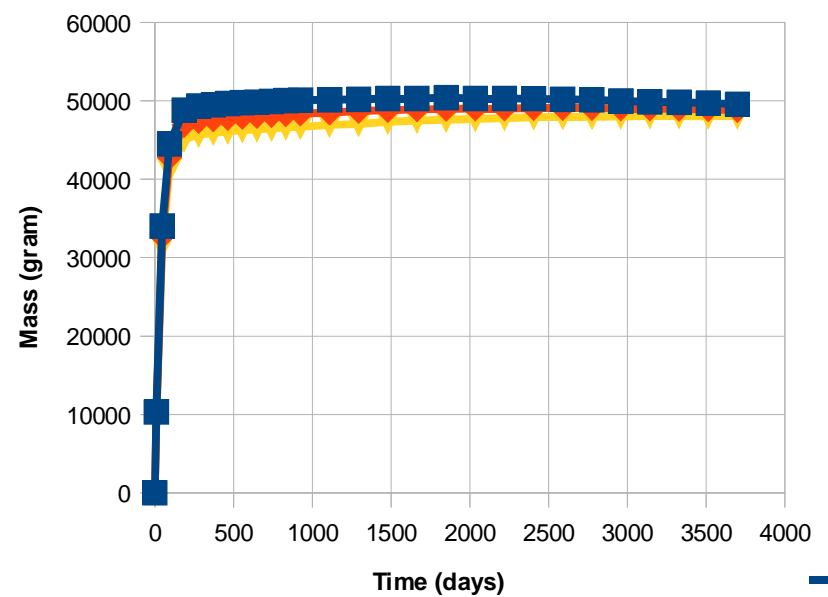

(a)

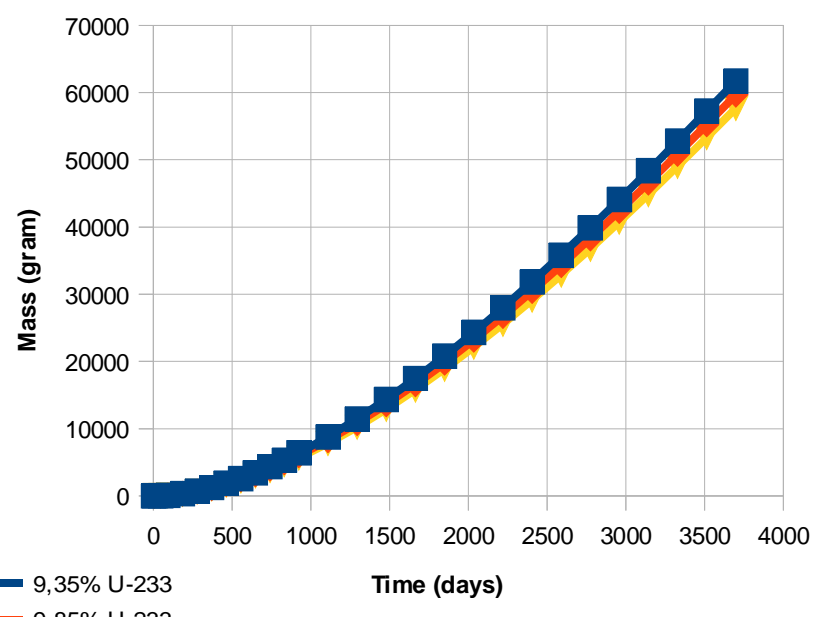

(b)

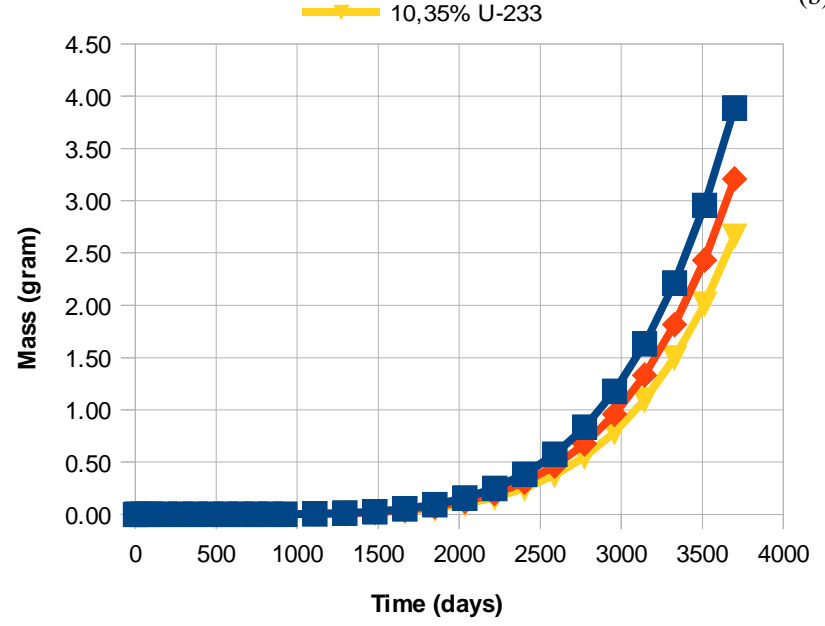

(c)

Fig 6. (a) Mass variation of ${ }^{233} \mathrm{~Pa}$. (b) Mass variation of ${ }^{235} \mathrm{U}$. (C) Mass variation of fissile plutonium $\left({ }^{239} \mathrm{Pu}+{ }^{241} \mathrm{Pu}\right.$ )

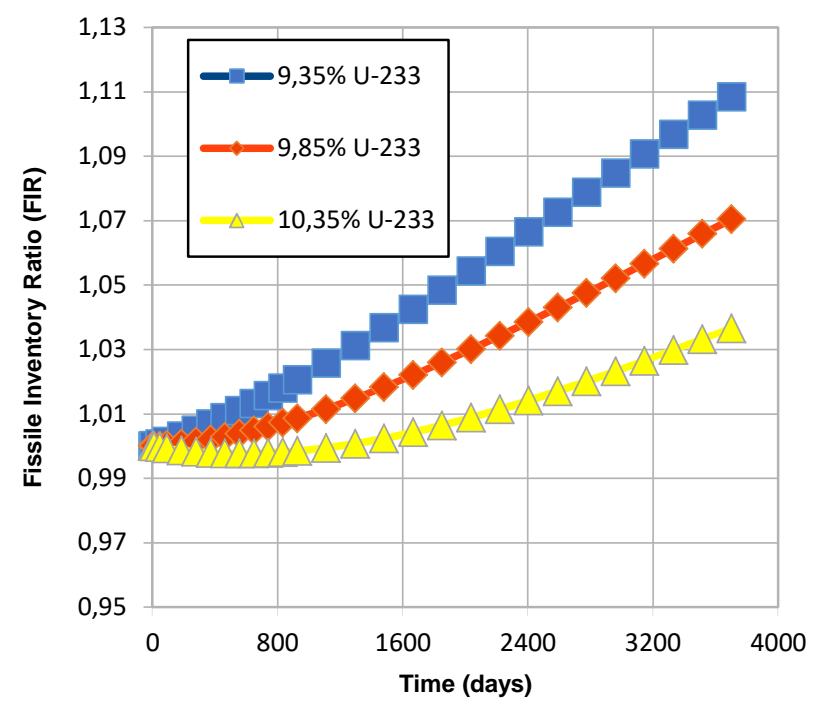

Fig 7. Variation of fissile inventory ratio (FIR) 


\section{CONCLUSIONS}

For the improvement of sustainable nuclear energy, a $1000 \mathrm{MWt}$ thorium fueled reduced moderation boiling water reactor (RBWR) was studied. The core burnup calculations were carried out on this reactor to evaluate the neutronic behavior. The impact of the initial fissile fuel content in the fissile zone on the reactor characteristics related to neutronic behavior such as the core burnup, fissile breeding and fissile inventory ratio (FIR) was analyzed.

The analysis indicated that the change in initial fissile fuel content in the fissile zone resulted in the opposite impact on the core burnup and fissile breeding. The low initial fissile fuel content in the fissile zone led to the low core burnup and high fissile breeding, and the opposite results were obtained with the high initial fissile fuel content in the fissile zone. The initial fissile fuel used in this study was ${ }^{233} \mathrm{U}$. In all ${ }^{233} \mathrm{U}$ content cases applied in this study, the FIR values of above 1 were obtained. It means that a fuel-self-sustaining system was achieved in this study. The targets of high fuel burnup and fuel-self-sustaining design were achieved with ${ }^{233} \mathrm{U}$ content in the fissile zone of $10.35 \%$. Even though in the $9.35 \%$ and $9.85 \%{ }^{233} \mathrm{U}$ content cases the FIR values are higher than that in the $10.35 \%{ }^{233} \mathrm{U}$ content case, but the fuel burnup of these configurations were smaller than that of the $10.35 \%$ configuration.

The results of inventory analysis indicated that ${ }^{233} \mathrm{~Pa}$ is a major factor in the fissile breeding of the thorium fuel cycle as it accumulates in the fuel in a considerable amount. By waiting for the entire ${ }^{233} \mathrm{~Pa}$ contained in the discharged fuel to undergo a beta decay to become ${ }^{233} \mathrm{U}$ during the cooling period before the reprocessing can take place, the amount of fissile fuel in the reprocessed fuel can be maximized. It also was found that the fissile plutonium $\left({ }^{239} \mathrm{Pu}\right.$ and $\left.{ }^{241} \mathrm{Pu}\right)$ inventory in the core was very small and much smaller than that of uranium $\left({ }^{233} \mathrm{U}\right.$ and $\left.{ }^{235} \mathrm{U}\right)$ and ${ }^{233} \mathrm{~Pa}$. From this result, there are two possible options for fissile plutonium utilization in the thorium fuel cycle: it can be safely disposed of as waste since its inventory in the discharged fuel is considerably less than that in $\mathrm{UO}_{2}$ spent fuel, or it can be recycled back to the core along with the uranium fissile. However, to maximize the sustainability and minimize the proliferation and radiotoxicity, recycling back the fissile plutonium to the core is a more likely excellent option.

From these results, it was confirmed that it is feasible to create a self-sustaining fuel cycle system using thorium fueled reduced moderation boiling water reactor (RBWR). However, there is a trade-off between the core burnup and fissile breeding that can be a significant challenge in the development of this system. Evaluating the other design variables may be considered to address this challenge. The further study to analyze the safety performances of the core is required to arrive at a safe and reliable reactor system.

\section{REFERENCES}

[1] F. Ganda, F. J. Arias, J. L. Vujic, and E. Greenspan, "Self-Sustaining Thorium Boiling Water Reactors", Sustainability, vol. 4, pp. 24722497, 2014.

[2] P. M. Gorman, J. L. Vujic, and E. Greenspan, "Trade-Off Studies for the Fuel-Self Sustaining RBWR-Th Core" Nuclear Technology, vol. 191, pp. 282-294, 2015.

[3] T. Hino, M. Ohtsuka, K. Moriya and M. Matsura, "Light Water Reactor System Designed to Minimize Environmental Burden of Radioactive Waste", Hitachi Review, Vol. 63, No. 9, 2014.

[4] Nuclear Energy Agency, Perspectives on Use of Thorium in the Nuclear Fuel Cycle, NEA No. 7228, 2015.

[5] H. Y. Choi, and C. J. Park, "Conceptual Design of Thorium Based Epithermal Spectrum Reactor”, Annals of Nuclear Energy, vol. 109, pp. 61-68, 2017.

[6] D. Medina-Castro, P. L. Hernandez-Adame, C. L. de Leon, L. SajoBohus, H. R. Vega-Carrillo, "Designing a Heterogeneous Subcritical Nuclear Reactor with Thorium-Based Fuel", Annals of Nuclear Energy, vol. 96, pp. 455-458, 2016.

[7] B. J. Lewis, E. N. Onder, and A. A. Prudil, Fundamentals of Nuclear Engineering, Chichester, West Sussex, United Kingdom: John Wiley \& Sons, Inc., 2017.

[8] J. Leppänen, M. Pusa, T. Viitanen, V. Valtavita, and T. Kaltiaisenaho, "The Serpent Monte Carlo Code: Status, Development and Applications in 2013", Annals of Nuclear Energy, Vol. 82, pp. 142-150, 2015.

[9] J. Leppänen, M. Pusa, and E. Fridman, "Overview of Methodology for Spatial Homogenization in the Serpent 2 Monte Carlo Code", Annals of Nuclear Energy, Vol. 92, pp. 126-136, 2016.

[10] Neil E. Todres and Mujid S. Kazimi, Nuclear System I: Thermal Hydraulic Fundamentals, $2^{\text {nd }}$ ed., Boca Raton, USA: CRC Press, 2011.

[11] M. Pusa, Numerical Methods for Nuclear Fuel Burnup Calculations, PhD Thesis, Aalto University, 2013.

[12] A. Isolato, Computational Methods for Burnup Calculations with Monte Carlo Neutronics, PhD thesis, Aalto University, 2013.

[13] D. Kotlyar and E. Shwageraus, "On the Use of Predictor-Corrector Method for Coupled Monte Carlo Burnup Codes", Annals of Nuclear Energy, vol. 58, pp. 228-237, 2013.

[14] A. Isotalo and V. Sahlberg, "Comparison of Neutronics-Depletion Coupling Schemes for Burnup Calculations", Nuclear Science and Engineering, vol. 179, pp. 434-459, 2015.

[15] M. Pusa, "Higher-Order Chebyshev Rational Approximation Method and Application to Burnup Equations", Nuclear Science and Engineering, vol. 182, pp. 297-318, 2017.

[16] V. Valtavirta, and J. Leppänen, "Coupled Burnup Calculations with the Serpent 2 Monte Carlo Code". In. Proc of $M \& C$ 2017, Jeju, Korea, 2017. 